\title{
Antecedents and Consequences of Student-Athletes' Contentment With Academic Services
}

\author{
Rammi N. Hazzaa \\ Katja Sonkeng \\ University of Northern Colorado \\ University of Georgia
}

\author{
Taeho Yoh \\ Southern Illinois University Carbondale
}

\begin{abstract}
The purpose of this study sought to investigate factors that influence studentathletes' satisfaction with academic services within athletics departments. Additionally, we examined the relationship between student-athletes' satisfaction and academic performance (i.e., GPA). A total of 226 NCAA Division I studentathletes from a Midwestern university competing in a mid-major conference participated. A survey consisting of 22 questions was created to assess the satisfaction of the four major factors (facilities, staff, tutoring, and advising programs) of academic advising services. Results revealed that student-athletes were satisfied with academic services, but satisfaction differed among class levels, with freshman athletes reporting lower levels of satisfaction than junior and senior athletes. Additional results showed that facilities and staff have significant influences on student-athletes' satisfaction with academic services. Furthermore, there was a significant relationship between student-athletes' satisfaction and GPA. The findings provide partial support for the proposed theoretical model, which suggests that athletics departments should provide adequate, accessible academic facilities and hire properly-trained staff.
\end{abstract}

Keywords: academic performance, advising, intercollegiate athletics

With intercollegiate athletics playing a major role in higher education in the United States, student-athletes are undoubtedly a major focus at most institutions. Growth in the commercialization of college athletics has shifted the focus from athletic participation to multifaceted business enterprises that emphasize winning at all costs (Adler \& Adler, 1991). Critics in higher education have argued that

Hazzaa is with the School of Sport and Exercise Science, University of Northern Colorado, Greeley, CO. Sonkeng is with the Department of Kinesiology, University of Georgia, Athens, GA. Yoh is with the Department of Kinesiology, Southern Illinois University Carbondale, Carbondale, IL. Address author correspondence to Rammi N. Hazzaa at rammi.hazzaa@unco.edu. 
universities are exploiting their athletes and failing to fulfill their educational obligations to them. Despite these claims, universities have begun a spending surge in academic support for athletes. Since 1997, the budgets for academic services for athletes have more than doubled, on average, to more than $\$ 1$ million a year (Wolverton, 2008). The increase in spending for lavish academic centers may allow players to hold on to their academic eligibility (Knight Commission on Intercollegiate Athletics, 2001), a worrisome reality for many programs prioritizing winning at all costs. Wolverton (2008) suggests that the academic spending boom is a combination of reduced admissions standards for prospective athletes coupled with more stringent National Collegiate Athletic Association (NCAA) academic-progress requirements.

In addition to increased support services for its student-athletes, new facilities are being constructed or refurbished within NCAA athletics departments. Athletic academic centers are being considered the "crown jewel" of athletic facilities and help to serve as a reminder of the institutions' priority toward academics (Wolverton, 2008). These actions by university officials and athletic directors are in line with a continued trend of increased athletic spending. A report by the Knight Commission on Intercollegiate Athletics (2014) quantified spending for studentathletes had increased $43 \%$ in nearly a decade, compared to only $6 \%$ for general college students. It appears many institutions, including the NCAA, are justifying the additional spending and academic support to reinforce their values for academic excellence. However, the Knight Commission on Intercollegiate Athletics (2001) suggests that the primary role of athletic centers for academic support is to keep student-athletes eligible, as opposed to the goal of completing a college degree.

Challenges for student-athletes include balancing the demands of preparing for a future career beyond a student and being successful on the field as an athlete (Yukhymenko-Lescroart, 2014). Consequently, student-athletes are faced with many responsibilities which require both mental and physical demands. For the large majority of collegiate athletes, the goal of becoming a professional athlete is not attainable. Therefore, it is crucial for them to take advantage of any available educational and personal development opportunities. Many student-athletes struggle with the notion of identity upon graduation, transitioning out of the athlete role and becoming a contributing member of society (Adler \& Adler, 1987). Thus, it is the collective responsibility of the NCAA, its member institutions, and athletics departments to provide student-athletes with resources and opportunities upon entering the workforce.

Although the development of academic excellence is one of the most vital missions of the NCAA and its member institutions, there is a dearth of empirical research on the factors influencing student-athletes' satisfaction with academic services. Additional research that considers the student-athlete perspective is warranted (Navarro \& Malvaso, 2016). With major college programs continuing to construct standalone academic centers exclusively for athletes, it might be beneficial to understand their perceptions toward these major investments. Russell (2015) stated, "understanding student-athlete satisfaction is of critical importance to the effective athletic organization, as meeting the needs of its student-athletes, the organization's primary constituents and producers of entertainment, is one of the main purposes for collegiate athletics" (p. 2). Findings from the present study 
might allow athletics administrators to hire more qualified personnel, purchase necessary equipment, and design effective programming, which supports the demands of student-athletes. Thus, the primary purpose of this study was to examine potential factors affecting student-athletes' satisfaction with academic advising services (i.e., personnel, facilities, services). Additionally, we sought to examine the relationship between student-athletes' satisfaction and academic performance (i.e., grade point average [GPA]).

\section{Literature Review}

Previous research on academics in collegiate athletics has primarily focused on eligibility, academic violations, and graduation rates (Broughton \& Neyer, 2001; Comeaux \& Harrison, 2011). Recently, more attention has been geared toward the lack of academic support for student-athletes, their poor academic achievements (i.e., degree completion), and the financial obligations of universities (Dillman, 2008). Studies on student-athletes' perceptions and contentment with academic advising services remain limited (Dillman, 2008; Huml, Hancock, \& Bergman, 2014). Although, student-athletes' satisfaction with academic advising has been found to be one of the most influential factors for academic performance (Dillman, 2008). However, there remains a lack of understanding and empirical evidence on the most effective means of organizing and delivering academic advising services to student-athletes (Cooper, 2001). The proposed model suggests four academic services (facilities, staff, tutoring, advising programs) may influence the satisfaction of student-athletes. We also propose student-athletes satisfied with academic services may, in turn, influence academic performance (GPA).

\section{Academic Advising in Higher Education}

As institutions continue to find new ways to recruit and retain students, quality academic advising has been recognized as a fundamental component of student retention (Allen \& Smith, 2008). Kuhn (2008) defined academic advising as "situations in which an institutional representative gives insight or direction to a college student about an academic, social, or personal matter" (p. 3). Previous research argues academic advising can directly affect students' persistence and likelihood of graduating, or have indirect effects through grades, intentions, or satisfaction with the student role (Pascarella \& Terenzini, 2005). Despite the link between academic advising and retention rates (Crockett, 1978), students are often dissatisfied with the advising they receive (Allen \& Smith, 2008).

Several decades ago, academic advising in higher education primarily focused on creating class schedules and monitoring degree requirements for students. Students would meet with their assigned academic advisor at the beginning of each semester and determine a course schedule to best fit his or her academic needs and aligns with career goals. More recently, however, academic support services are gradually becoming more prominent across public and private institutions. King (1993) alluded to academic advising as the only structured service on college campuses that guarantees students interactions with concerned representatives of the institution. Many programs now employ several advisors and administrative 
professionals who work with department chairs and faculty to best serve the student population. These advising centers on campus also operate as multifunctional departments, which are responsible for overseeing academic progress for students, as well as increasing retention and graduation rates (Kuhn, 2008). Their particular strength on campuses is providing guidance and establishing connections to other student support services (King, 1993). Aside from other academic programs, academic advising has generally become the primary and most valued source for students when seeking advice on academic, social, or personal matters (Kuhn, 2008). Institutions have now begun to acknowledge the importance of quality advising and how such efforts can have an impact on students pursuing their educational goals.

\section{Academic Support Services for Student-Athletes}

Academic advising has become an integral part of the college experience for both "regular" students and college athletes, as they enroll at a university essentially with the same academic, emotional, and personal goals (Ferrante \& Etzel, 1991). To address this belief, the NCAA has made huge strides within the past 20 years to provide student-athletes with the best resources and opportunities to achieve their athletic and educational pursuits. For example, the NCAA requires its member institutions to make academic counseling and support services available to all student-athletes (NCAA, 2017b). In addition, many athletics departments are hiring full-time academic advisors to specifically work with only student-athletes. In an effort to reward academic success across all divisions of the NCAA, several awards were created to acknowledge team accomplishments each academic year.

Previous scholars have found student-athletes express the need for academic support from their athletics departments (Huml et al., 2014). Bell (2009) contends that student-athletes contact their academic advisor first for any academic issues, questions, or concerns. Through the advising process, student-athletes build a strong bond with their athletic advisors due to spending a majority of their day away from practice with them and learning about how to best approach daily habits and routines. In some instances, academic support from advisors is not always on the student-athlete side. Coaches may sometimes influence advisors into urging student-athletes to register for certain classes that do not interfere with practice, film sessions, or competition. For example, Hardin and Pate (2013) found a common practice for advisors is to schedule classes for student-athletes without any of their personal input and designing their academic programs with the sole intention of ensuring eligibility (Simons, Van Rheenen, \& Convington, 1999).

\section{NCAA Academic Standards}

The NCAA serves to oversee all facets of collegiate athletics as well as provide resources and support. It has stated that the ultimate goal of the student-athlete college experience is graduation. They provide its member institutions with significant funding for programming and staffing resources for the large purpose of ensuring the academic success and graduation of student-athletes (Gruber, 2003). The NCAA also sets forth academic eligibility standards which take into account GPA, standardized test scores, and core courses completed in high school 
(NCAA, 2017a). All student-athletes must meet these unique requirements for university admissions.

In 2003, the NCAA implemented the Academic Progress Rate (APR) to measure student-athletes' academic performance and hold institutions accountable for monitoring academic progress (NCAA, 2017a). This system was designed to examine student-athletes through a team-based metric that accounts for eligibility and retention each academic term. A team may jeopardize their players' scholarships if they fail to maintain a minimum score of .925 , equivalent to $92.5 \%$ (Dillman, 2008), which refers to the percentage of student-athletes progressing toward a degree and staying academically eligible each academic term (NCAA, 2017a). Along with APR, the NCAA developed the Graduation Success Rate (GSR) for Division I, and the Academic Success Rate (ASR) for Division II, which requires all colleges and universities to report student-athletes' degree progression and completion rates. If athletics teams do not achieve the minimum threshold scores, those teams are subject to various sanctions such as the loss of scholarships, practice time availability, postseason bans, and restriction of membership status (NCAA, 2017b).

\section{Dual Role of Student-Athletes}

Previous literature examining the experiences of student-athletes has been robust (Adler \& Adler, 1987, 1991; Miller \& Kerr, 2002). Student-athletes often struggle with understanding and recognizing their dual role as both a student and athlete. Particularly, the transition from high school to college often proves to be a challenge for student-athletes as they frequently struggle to adjust to the balancing act between coursework and athletic commitment (Lally \& Kerr, 2005). Studentathletes are also often forced to make a number of compromises with their own autonomy (Adler \& Adler, 1987; Miller \& Kerr, 2002). As a result, student-athletes may view themselves primarily as either students or athletes (YukhymenkoLescroart, 2014). Russell (2015) found student-athletes who fail to successfully adjust to their new environment and academic demands during their first year are less likely to return or remain eligible for participation. According to Pascarella et al. (1999), this adjustment process, in addition to willingness to persist, and student retention is associated with student-athletes' self-confidence and satisfaction with his or her personal self.

Socialization and connecting with nonathletes on campus has also been an area of concern for student-athletes. Adler and Adler (1991) contend that a separate academic facility within an athletics department can decrease the probability of student-athletes connecting with other students and higher education entities. Due to their time commitments, student-athletes are often prone to becoming isolated from other areas on campus. Student-athletes may also be subject to required study halls, in which their academic interactions are limited to other student-athletes or teammates and their athletic advisors (Adler \& Adler 1991). While such requirements may lead to stronger relationships with teammates and advisors, the lack of interaction opportunities with other nonathletes, and the unique experience of the college environment, could result in missed opportunities.

Yet ironically, the balancing act between the classroom and the field is often undervalued, and student-athletes are often viewed with persistent stereotypes and 
derogatory labels such as having a lack of motivation or interest, and lacking the necessary intellectual abilities to perform well academically (Russell, 2015). These limited views often undermine the unique physical, emotional, and psychological demands expected of student-athletes. In addition to the challenges every student encounters, such as social adjustment, career exploration, and intellectual growth, student-athletes have to cope with great time demands and a high level of commitments, which are deeply entwined with their dual role as student and athlete (Adler \& Adler, 1991). For example, student-athletes attend mandatory study halls, participate in practices, and travel across the country for competition. As a result, time and effort spent as a student becomes limited and less important. In 1991, the NCAA implemented regulations to limit practice time to no more than $4 \mathrm{hr}$ per day and $20 \mathrm{hr}$ per week in structured athletic activities (e.g., practice, competition, conditioning, team meetings). However, a 2011 NCAA survey on the student-athletes' experiences revealed the average number of hours spent per week on athletic activities in-season was more than $40 \mathrm{hr}$ in most sports (NCAA, 2011). Oftentimes, practices start as early as 6 a.m., followed by afternoon classes, a possible afternoon practice, then an evening of homework and studying. Despite student-athletes having limited time to keep up with academic demands, studentathletes are still expected to perform at a high level during athletic competitions.

\section{Conceptual Framework}

Although there has been a considerable body of research on student-athletes in the sport management literature, there has been limited research regarding academic development resources for student-athletes. Student-athletes' satisfaction with academic advising has been proven to be one of the most influential factors for individual academic performance (Dillman, 2008). Therefore, the purpose of the present study sought to examine the antecedents and consequences of NCAA Division I student-athletes' satisfaction toward academic advising services. In the proposed theoretical model, antecedents of satisfaction include: facilities, staff, tutoring, and advising programs. These antecedents influence student-athletes' satisfaction with academic services, which in turn influences student-athletes' academic performance (GPA). The proposed theoretical model of satisfaction with academic services is presented in Figure 1.

\section{Antecedents of Satisfaction With Academic Services}

Facilities. In a university setting, the physical facilities for athletics are primarily comprised of administrators, coaches, and other services for student-athletes. However, a majority of athletics departments are now constructing or refurbishing facilities for the sole purpose of expanding or adding new academic support services for student-athletes (Huml et al., 2014; Wolverton, 2008). State-of-the-art athletic academic centers are now considered the "crown jewel" of many athletic facilities (Wolverton, 2008). In addition, tangible elements of a facility (e.g., layout, accessibility, resources, etc.) have been found to be one of the significant predictors of consumer satisfaction (Yoshida \& James, 2010). Hence, the first hypothesis is stated as follows: 


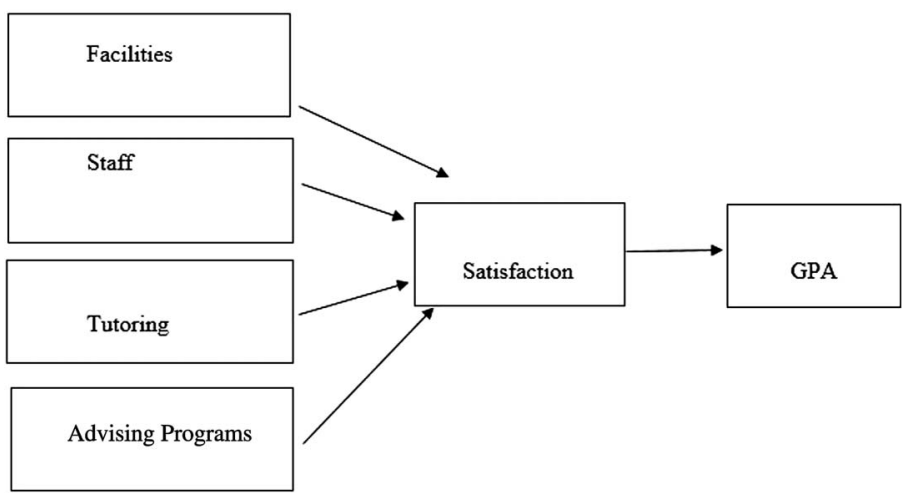

Figure 1 - Conceptual model testing hypotheses of antecedents and consequences of academic services. GPA = grade point average.

H1: Advising facilities will have a positive influence on student-athletes' satisfaction with academic services.

Staff. Within an academic advising center, staff typically includes academic advisors, graduate assistants, and additional administrative personnel. According to Pascarella and Terenzini (2005), many college students are often dissatisfied with the advising they receive. Levels of dissatisfaction with academic advising among students is particularly due to the individuals (i.e., faculty, professional advisors) providing advising services (Allen \& Smith, 2008). As such, students value their relationships with academic advisors and academic staff that develops over time (Roberts \& Styron, 2010). A knowledgeable, well-trained advising staff which can deliver effective advising to student-athletes is important for their academic and professional development. It is common for student-athletes to build strong bonds with their advisors and seek their advice on academic issues or questions (Bell, 2009). Hence, the second hypothesis is stated as follows:

H2: Advising staff will have a positive influence on student-athletes' satisfaction with academic services.

Tutoring. Tutoring refers to an individual who is knowledgeable in a specific content area and in instructing others on important concepts (Topping, 1996). More recently, peer tutoring has become common at many universities for students seeking extra instruction in a particular content area. Academic centers for studentathletes are beginning to hire students specifically for helping athletes manage their coursework. For example, the University of Southern California spends \$1.5 million annually on staffing tutors and other support staff for its student-athletes (Thamel, 2006). Hence, the third hypothesis is stated as follows:

H3: Academic tutoring will have a positive influence on student-athletes' satisfaction with academic services. 
Advising programs. Advising has been consistently shown to contribute to student retention (Pascarella \& Terenzini, 2005). Many student-athletes feeling the pressure of staying eligible and keeping an athletic scholarship have requested increased academic support (Huml et al., 2014). Therefore, a potential for satisfaction is offering advising programs for student-athletes that directly contribute to developing educational and career goals. Hence, the fourth hypothesis is stated as follows:

H4: Advising programs will have a positive influence on student-athletes' satisfaction with academic services.

Academic performance (GPA). Academic performance refers to studentathletes' self-reported GPA in the present study. Student-athletes' satisfaction with academic advising has been proven to be one of the most influential factors for individual academic performance (Dillman, 2008). Academic motivation was found to be a strong predictor of future students' academic success (Gaston-Gayles, 2004). Metzner (1989) found high-quality advising positively influenced GPA and freshman student satisfaction. Hence, the fifth hypothesis is stated as follows:

H5: Satisfaction with antecedents of academic services will have a positive influence on student-athletes' academic performance (GPA).

\section{Methods}

\section{Participants}

A total of 226 student-athletes from an NCAA Division I institution competing in a mid-major conference from the Midwest participated in this study. The participants were comprised of all undergraduate levels from both team and individual sports. Specifically, there were 62 freshmen, 63 sophomores, 47 juniors, and 54 seniors. The athletics department has five academic service staff and more than 15 students across campus to serve as tutors for student-athletes. Each participant was at least 18 years of age and provided verbal and written consent, per Institutional Review Board (IRB) approval. Participants were notified that the survey was anonymous, and all responses would be kept completely confidential and had no affiliation with the athletics department, advising center, or teams.

\section{Instrumentation}

The initial instrument was created through interviews with student-athletes and a review of the related literature. A pilot study with 52 student-athletes was designed to assess the reliability and validity of the instrument. The initial questionnaire consisted of 20 questions, including five demographic questions (gender, grade level, race, GPA, sport). However, following the results of a factor analysis, the total number of questions was reduced to 17 items, and the four major factors were determined. Those factors included tutoring (4 items), academic support programs (5 items), advising staff (4 items), and advising facilities (4 items). Each item consisted of a 5-point Likert scale, ranging from 1 (strongly disagree) to 5 (strongly agree), which was used to measure student-athletes' overall satisfaction 
with academic services and their benefits to the participants. The consequence of student-athletes' satisfaction with academic services is academic performance (GPA).

The composite reliabilities (Cronbach $\alpha$ ) of the four factors ranged from .78 (facilities) to .89 (staff). The average variance extracted (AVE) of the four constructs ranged from .56 to .65 , which exceeds the .5 threshold and is greater than the squared correlation (.434) between the four constructs (Fornell \& Larcker, 1981). Hence, the discriminant validity was also supported by the four factors. For the convergent validity, all estimated loadings of indicators for the underlying constructs were significant. The confirmatory factor analysis (CFA) goodnessof-fit (GOF) statistics showed the chi-square was significant $\left(\chi^{2}=131.57, p<.01\right)$. However, as Hair, Black, Babin, and Anderson (2010) suggested, it is not recommended to solely use the $\chi^{2}$ GOF test because this statistic will be affected by several factors, such as sample size, model size, and the distribution of variables. Thus, other GOF indices (GFI, CFI, and RMSEA), which are less sensitive to sample size and other factors, were examined. Hair et al. (2010) indicated that these three GOF indices provide sufficient information to evaluate the model fit. The goodness-of-fit index $(\mathrm{GFI}=.89)$ was close to the acceptable model fit index value (.90 or greater) (Hooper, Couglan, \& Mullen, 2008; Marsh \& Grayson, 1995; Schumacker \& Lomax, 1996). Further, the value of adjusted goodness-of-fit index (AGFI) was .87, which is greater than acceptable value (.85 or greater) (Schaffer, 2008; Schermelleh-Engel, Moosbrugger, \& Muller, 2003). For other indices, the comparative fit index (CFI), which is used to assess model fit due to its resistance to errors associated with sample size, and above .90 is generally associated with good fit, was .91 $(\mathrm{CFI}=.91)$. The root mean square error of approximation (RMSEA) was .071, considering an acceptable RMSEA in a well-fitting model should be less than .08 (Hair et al., 2010). Thus, the measures of the GOF indices indicated the model fit lies in an acceptable level. The proposed theoretical model also revealed that the four antecedents explained $64 \%$ of the variance in student-athletes' satisfaction with academic services.

\section{Data Analysis}

Based on the nature of this study and our aim to provide an understanding of academic advising issues within athletics departments, the data analysis consisted of several tests aimed at addressing the proposed conceptual model and five hypotheses. Descriptive statistics were used to identify frequencies of class level, sport, and gender. Analysis of variance (ANOVA) was used to examine satisfaction differences among student-athlete class levels. ANOVA was followed up with a post hoc Tukey test to identify significant differences among student-athlete class levels. Lastly, path analysis was performed to test for statistical significance among the four major factors of satisfaction with academic services.

\section{Results}

Descriptive statistics revealed student-athletes' overall satisfaction with academic services was considerably high $(M=4.17, S D=.57)$. Among the four major factors 
of academic services (see Table 1), the quality of the advising facilities $(M=4.32$, $S D=.45)$ received the highest satisfaction response from student-athletes, followed by the advising staff $(M=4.21, S D=.52)$, tutoring, $(M=4.11, S D=.56)$, and the advising programs $(M=3.79, S D=.63)$.

Further, the results of ANOVA suggest the overall satisfaction with academic services significantly differed $(F=3.657, d f=221, p=.008)$ among student-athlete class levels. Freshman athletes reported lower levels of contentment than upperclassmen (e.g., junior and senior standing). Table 2 shows the means and standard deviations across grade levels obtained through ANOVA to determine differences among the four groups. Specifically, a post hoc Tukey test showed that there was a significant statistical difference between freshmen and juniors $(p=.017)$ and freshmen and seniors $(p=.038)$ on the overall satisfaction with academic services. In addition, ANOVA revealed no significant differences between gender, race, and type of sport.

Furthermore, a path analysis revealed the overall influence of the four major factors on the satisfaction of student-athletes was significant $(F=105.160, d f=$ $221, p<.001$ ). The results (see Figure 2) also indicated the four antecedents of academic services explained $64 \%$ of the variance in student-athletes' overall satisfaction. More specifically, the results showed the quality of advising facilities was found to have significant influences on student-athletes' satisfaction with academic services $(\beta=.417, p<.001)$. Thus, hypothesis 1 was supported. For hypothesis 2 , the results suggested the advising staff $(\beta=.173, p<.003)$ played an important role in student-athletes' satisfaction. Therefore, hypothesis 2 was supported. The results also showed that the influence of a tutoring and advising program did not significantly influence satisfaction. Thus, hypotheses 3 and 4 were not supported as antecedents. Finally, a path analysis was also used to investigate

\section{Table 1 Means and Standard Deviations of Academic Advising Factors}

\begin{tabular}{lcc}
\hline Factors & Mean & SD \\
\hline Facility & 4.32 & 0.45 \\
Staff & 4.21 & 0.52 \\
Tutoring & 4.08 & 0.58 \\
Program & 3.80 & 0.62 \\
\hline
\end{tabular}

Table 2 Means and Standard Deviations from Overall Satisfaction of Academic Services

\begin{tabular}{lcc}
\hline Grade Levels & Mean & SD \\
\hline Freshman & 3.67 & 0.61 \\
Sophomore & 3.94 & 0.57 \\
Junior & 4.29 & 0.53 \\
Senior & 4.19 & 0.46 \\
\hline
\end{tabular}




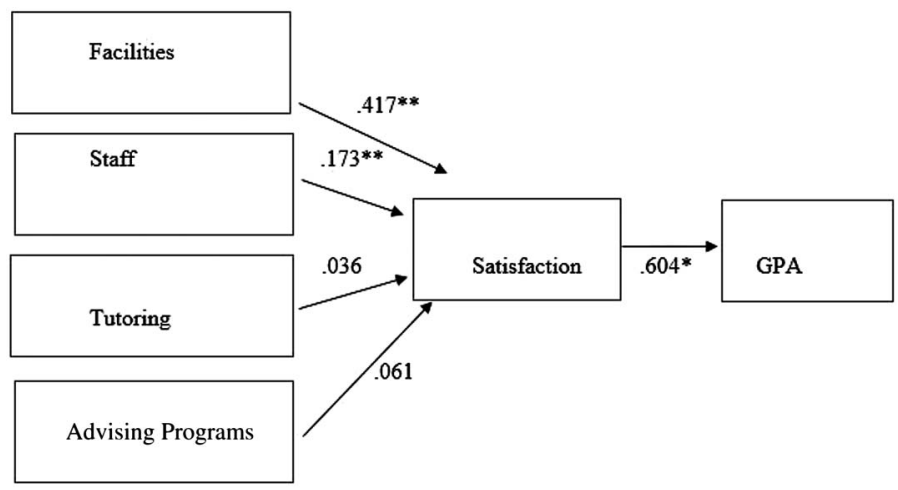

Figure 2 - Results of conceptual model testing hypotheses of antecedents and consequences of academic services with standardized estimates from path analysis. ${ }^{*} p<.05$. $* * p<.01 . \mathrm{GPA}=$ grade point average.

hypothesis 5 that academic services mediates improved academic performance on satisfaction. Results indicated that student-athletes' GPAs were a significant predictor of the four factors of academic services $(\beta=.60, p<.05)$. In other words, satisfaction played a significant role on student-athletes' GPAs. Therefore, hypothesis 5 was supported.

\section{Discussion}

The purpose of this study was to gain further insight into the factors that influence satisfaction of academic services provided to college student-athletes and the effect of satisfaction on their academic performance (i.e., GPA). A conceptual model was proposed and empirically tested which explained the relationship among the antecedents and consequences of satisfaction with academic advising services. Facilities and staff were found to be important determinants of advising satisfaction, which positively influenced academic performance. Previous research suggested adequate physical, human, and financial resources, coupled with institutional spending, may lead to greater academic benefits for the institution (Astin, 1984; Toutkoushian \& Smart, 2001). Those benefits may include enhanced student outcomes such as student learning and degree completion (Astin, 1993). Additional support has demonstrated that investing in relevant and sufficient resources for student-athletes may increase the likelihood of persisting through to degree completion (Kamusoko \& Pemberton, 2011). Findings from this study support previous research, while adding to the growing body of literature on understanding collegiate student-athletes' interest, appreciation, and satisfaction of athletic academic support (Bell, 2009; Dillman, 2008; Huml et al., 2014). For instance, the authors of the present study have attempted to shed light on the importance for collegiate athletics departments to provide accessible, 
well-maintained state-of-the-art academic facilities, and staff them with friendly and dedicated academic personnel to serve student-athletes.

Within the proposed model, differences in gender and type of sport (team versus individual sports) were tested but no significant differences were found. Kamusoko and Pemberton (2011) found significant differences among gender, with females expressing greater levels of satisfaction and academic persistence. However, findings did reveal significant differences among student-athletes' grade levels. Upperclassmen reported higher satisfaction scores for academic services than underclassmen. This particular finding may be due to older student-athletes having more time and experience with academic services. Ridpath (2010) suggested academic support for collegiate athletics programs are primarily regarded as a means to maintain eligibility, especially for revenue-generating sports such as basketball and football. While no significant differences were found regarding the type of sport, comparing revenue-generating sports may have yielded different results. For example, a qualitative study examined student-athletes' perceptions of culture within academic centers (Rubin \& Moses, 2017). The authors found female student-athletes believed male student-athletes in revenue-generating sports took advantage of the academic resources by not doing much of their own work. Perhaps this is due in large part to greater demands placed on those studentathletes, overzealous confidence, lack of academic motivation, or poor high school academic records before entering higher education. Considering the majority of male and female student-athletes will not compete at a professional level, it is imperative for athletic advisors, coaches, and athletic administrators to encourage student-athletes to make meaningful connections with advisors and seek additional support if necessary.

Lower feelings of self-efficacy have also been reported by student-athletes, more so than their nonathlete college counterparts (Burns, Jasinski, Dunn, \& Fletcher, 2013; Hardin \& Pate, 2013). A strong predictor of future students' success was the level of academic motivation (Gaston-Gayles, 2004). However, many student-athletes often struggle with balancing athletic and academic motivation (Simons et al., 1999). This may be primarily due to not having control over their class schedules, study hall hours, practice times, and competition. An important facet of being a successful college student is the opportunity to take an active role in managing various responsibilities. Russell (2015) stated, "satisfaction with academic support services is unequivocally the highest area of positive correlation with a student-athlete's adjustment to college" (p. vi). Our findings support this notion that student-athletes' satisfaction may have a significant impact on academic performance (i.e., GPA). Considering the significantly lower satisfaction responses from freshmen, it may be particularly useful for athletics academic service staff to create and develop effective strategies for managing the student-athletes' academic transition from high school to college.

As previously mentioned, student-athletes face many challenges during their college tenure, including balancing the demands of preparing for a future career beyond a student and being successful on the field as an athlete (YukhymenkoLescroart, 2014). For some student-athletes, excelling in their dual role of student and athlete can be difficult and potentially problematic. By recognizing these academic advising factors that matter most to student-athletes, athletics department personnel can hopefully address any potential concerns, identify areas of advising 
where students are struggling, and prepare student-athletes with the necessary tools for academic success and a future career. When athletics departments are effective and catering to student needs, these factors may increase athletes' satisfaction with the collegiate experience and promote continued persistence toward completing a degree (Pascarella et al., 1999).

The findings of this study provide several practical recommendations for academic service personnel working with student-athletes. First, athletics departments should make sufficient efforts to provide clean and comfortable academic service facilities for its student-athletes. This includes well-maintained and stateof-the-art equipment for academic services, such as computers, printers, and study desks. In addition, hiring approachable and courteous athletics service staff (i.e., advisors, graduate assistants) may give student-athletes extra confidence to seek out academic help and guidance on a regular basis. Second, athletics departments should continuously assess the academic needs of its student-athletes. In particular, by creating academic advising programs that specifically cater to student-athletes and their academic pursuits. For instance, student-athletes have expressed a desire for additional services such as career development, information about on-campus activities, and internships (Rubin \& Moses, 2017). By adding specific programs and academic services, student-athletes can shift the academic culture within collegiate athletics. Programs may begin to see an increase in academic performance from student-athletes and an upward trend in degree completion rates. As the findings of this study suggest, student-athletes' satisfaction with academic services is positively associated with academic performance (GPA). Further research is warranted to help better understand how satisfaction from academic services explains student-athletes' improvements in academic performance.

This study contributes to the growing body of research on academic development resources for student-athletes by proposing a conceptual framework explaining the antecedents and consequences of satisfaction with academic services among student-athletes. Huml et al. (2014) doubts the potential impact of athletic academic centers on the academic success of student-athletes. However, findings from the present study suggest a positive relationship between satisfaction with academic services and academic performance. These results offer potential implications to athletics departments investing in the academic success and eligibility of student-athletes. Further, we argue that high levels of satisfaction with academic services may lead to student-athletes improving their academic performance. Among the four antecedents in the study, we recommend athletics administrators primarily focus on the two antecedents (facilities and staff), which were found to positively affect student-athletes' satisfaction. Understanding the potential value of a state-of-the-art academic facility and a well-trained academic support staff may assist to satisfy and improve student-athletes' academic performance and, in turn, maintain their eligibility.

\section{Limitations and Future Research}

Considering the setting in which the study was conducted, the findings may be limited by a few key factors. First, the sample came from one NCAA Division I institution in the Midwest, hence the results may be applicable for this particular institution or geographic area. It would be suggested for future research to gather 
data from NCAA student-athletes across several institutions. Second, the survey questionnaire was conducted over a year-long period and representation may reflect only that time period, including the current condition of the academic center, advisors, and other services. Despite the anonymity of the study, it was possible some student-athletes may have been reluctant to share their actual perceptions of the advising center as a current student. Lastly, it should be mentioned that although the goodness-of-fit indices are in the acceptable ranges, they lie in the low range of acceptable model fit. Thus, the results should be interpreted carefully, and it is recommended to employ modification techniques to improve the model fit.

This study also provides several new avenues for future research. First, a future study could employ a comparative analysis of specific academic advising services provided by athletics programs since many offer a variety of educational resources. Second, it would be interesting for researchers to explore studentathletes' motifs and drivers to seek out academic services. This may include seeking out academic services to maintain eligibility, intrinsic motivation for academic success, or just being required to by their team or coach. Third, satisfaction and expectations on academic services may vary among studentathletes in different NCAA divisions or conferences. This would be an interesting area to investigate further, because athletics departments in the Power Five conferences are more likely to have greater available financial resources to support student-athletes. Larger state schools have invested millions of dollars into academic support facilities and services (Huml et al., 2014). While the present study found no differences in satisfaction among sports, it may also be valuable to explore the dichotomy between Division I student-athletes in revenue sports and nonrevenue sports.

The purpose of this study sought to investigate the potential factors influencing student-athletes' satisfaction with academic services in athletics departments. Additionally, we examined the relationship between student-athletes' satisfaction and academic performance (i.e., GPA). The present study also provides additional understanding into the perceptions of student-athletes and their satisfaction with academic services. Since athletics departments continue to invest a lot of financial and human resources into academic centers and services, findings from this study encourage athletics administrators to offer programs that align with the academic needs of student-athletes. Future research may examine the impact of specific academic programs and services on student-athlete development.

\section{References}

Adler, P., \& Adler, P.A. (1987). Role conflict and identity salience: College athletics and the academic role. The Social Science Journal, 24, 443-455. doi:10.1016/0362-3319 (87)90059-0

Adler, P.A., \& Adler, P. (1991). Backboards and blackboards: College athletes and role engulfment. New York, NY: Columbia University Press.

Allen, J.M., \& Smith, C.L. (2008). Importance of, responsibility for, and satisfaction with academic advisng: A faculty perspective. Journal of College Student Development, 49, 397-410. doi:10.1353/csd.0.0033

Astin, A.W. (1984). Student involvement: A developmental theory for higher education. Journal of College Student Personnel, 25, 297-308. 
Astin, A.W. (1993). What matters in college? Four critical years revisited. San Francisco, CA: Jossey-Bass, Inc.

Bell, L.F. (2009). Examining academic role-set influence on the student-athlete experience. Journal of Issues in Intercollegiate Athletics, 2, 19-41.

Broughton, E., \& Neyer, M. (2001). Advising and counseling student-athletes. New Directions for Student Services, 93, 47-55. doi:10.1002/ss.4

Burns, G.N., Jasinski, D., Dunn, S., \& Fletcher, D. (2013). Academic support services and career decision-making self-efficacy in student-athletes. The Career Development Quarterly, 61, 161-167. doi:10.1002/j.2161-0045.2013.00044.x

Comeaux, E., \& Harrison, K. (2011). A conceptual model of academic success for student-athletes. Educational Researcher, 40, 235-245. doi:10.3102/0013189X 11415260

Cooper, D.L. (2001). Assessing advising style: Student perceptions of academic advisors. College Student Affairs Journal, 20, 53-60.

Crockett, D.S. (1978). Academic advising: A cornerstone of student retention. New Directions for Student Services, 3, 29-35. doi:10.1002/ss.37119780306

Dillman, P.H. (2008). Differences in the opinions and attitudes of student athletes relative to expenditures for intercollegiate athletic support services (social, athletic, and academic) (Unpublished doctoral dissertation). Johnson City, Tennessee: East Tennessee State University.

Ferrante, A.P., \& Etzel, E. (1991). Counseling college student athletes: Issues and interventions. Morgantown, WV: Fitness Information Technology.

Fornell, C., \& Larcker, D.F. (1981). Evaluating structural equation models with unobservable variables and measurement error. Journal of Marketing Research, 18, 39-50. doi: $10.2307 / 3151312$

Gaston-Gayles, J.L. (2004). Examining academic and athletic motivation among student athletes at a division I university. Journal of College Student Development, 45, 75-83. doi:10.1353/csd.2004.0005

Gruber, C.A. (2003). What every academic advisor should know about advising student athletes. NACADA Journal, 23, 44-49. doi:10.12930/0271-9517-23.1-2.44

Hair, J.F., Black, W.C., Babin, B.J., \& Anderson, R.E. (2010). Multivariate data analysis (7th ed.). New York, NY: Pearson.

Hardin, R., \& Pate, J.R. (2013). Playbook vs. textbook: Examining academic transitioning of NCAA Division I-FBS football student-athletes. Journal for the Study of Sports \& Athletes in Education, 7, 229-244. doi:10.1179/1935739713Z.00000000014

Hooper, D., Couglan, J., \& Mullen, M.R. (2008). Structural equation modeling: Guidelines for determining model fit. Business Research Methods, 6, 53-60.

Huml, M., Hancock, M., \& Bergman, M. (2014). Additional support or extravagant cost? Student-athletes' perceptions on athletic academic centers. Journal of Issues in Intercollegiate Athletics, 7, 410-430.

Kamusoko, S.D., \& Pemberton, C.L. (2011). Student-athlete wellbeing and higher education persistence. Journal of Issues in Intercollegiate Athletics, 4, 207-235.

King, M.C. (1993). Organizing and delivering services for student success. New directions for community colleges. San Francisco, CA: Jossey-Bass, Inc.

Knight Commission on Intercollegiate Athletics. (2001). A call to action: Reconnecting college sport and higher education. Retrieved from https://www.knightcommission. org/wp-content/uploads/2008/10/2001_knight_report.pdf

Knight Commission on Intercollegiate Athletics. (2014). Trends in spending and institutional funding. Retrieved from http://spendingdatabase.knightcommission.org/fbs

Kuhn, T.L. (2008). Historical foundations of academic advising. In V.N. Gordon, W.R. Habley, T.J. Grites, \& Associates (Eds.), Academic advising: A comprehensive handbook (pp. 3-17). Manhattan, KS: National Academic Advising Association. 
Lally, P.S., Kerr, G.A. (2005). The career planning, athletic identity, and student role identity of intercollegiate student athletes. Research Quarterly for Exercise and Sport, 76, 275-285. doi:10.1080/02701367.2005.10599299

Marsh, H.W., \& Grayson, D. (1995). Latent variable models of multitrait-multimethod data. In R.H. Hoyle (Ed.), Structural equation modeling: Concepts, issues, and applications (pp. 177-198). Thousand Oaks, CA: Sage.

Metzner, B.S. (1989). Perceived quality of academic advising: The effect on freshman attrition. American Educational Research Journal, 26, 422-442. doi:10.3102/ 00028312026003422

Miller, P.S., \& Kerr, G. (2002). The athletic, academic and social experiences of intercollegiate student-athletes. Journal of Sport Behavior, 25, 346-367.

Navarro, K.M., \& Malvaso, S. (2016). Millennial student-athletes and career development: Toward an understanding of academic, athletic and parental spheres of influence on career aspirations and undergraduate major choices. College Student Affairs Journal, 34, 30-47. doi:10.1353/csj.2016.0017

NCAA. (2011). Division I results from the NCAA goals study on the student-athlete experience. Retrieved from https://www.ncaa.org/sites/default/files/DI_GOALS_ FARA_final_1.pdf

NCAA. (2017a). Academic progress rate (APR). Retrieved from http://www.ncaa.org/ about/resources/research/division-i-academic-progress-rate-apr

NCAA. (2017b). Graduation rates. Retrieved from http://www.ncaa.org/about/resources/ research/graduation-rates

Pascarella, E.T., \& Terenzini, P.T. (2005). How college affects students: Vol. 2. A third decade of research. San Francisco, CA: Jossey-Bass.

Pascarella, E.T., Truckenmiller, R., Nora, A., Terenzini, P.T., Edison, M., \& Hagedorn, L.S. (1999). Cognitive impacts of intercollegiate athletic participation: Some further evidence. The Journal of Higher Education, 70, 1-26.

Ridpath, B.D. (2010). Perceptions of NCAA Division I athletes on motivations concerning the use of specialized academic support services in the era of the academic progress rate. Journal of Issues in Intercollegiate Athletics, 3, 253-271.

Roberts, J., \& Styron, R. (2010). Student satisfaction and persistence: Factors vital to student retention. Research in Higher Education Journal, 6, 1-18.

Rubin, L.M., \& Moses, R.A. (2017). Athletic subculture within student-athlete academic centers. Sociology of Sport Journal, 34, 317-328. doi:10.1123/ssj.2016-0138

Russell, B.C. (2015). An examination of the relationship between athletic satisfaction and student adaption to college (Unpublished doctoral dissertation). University of Tennessee, Knoxville, Tennessee.

Schaffer, U. (2008). Management accounting and control scales handbook. Wiesbaden, HR: Deutscher Universitätsverlag.

Schermelleh-Engel, K., Moosbrugger, H., \& Muller, H. (2003). Evaluating the fit of structural equation models: Tests of significance and descriptive goodness-of-fit measures. Methods of Psychological Research, 8, 23-74.

Schumacker, R.E., \& Lomax, R.G. (1996). A beginners guide to structural equation modeling. Hillside, NJ: Erlbaum.

Simons, H.D., Van Rheenen, D., \& Covington, M.V. (1999). Academic motivation and the student-athlete. Journal of College Student Development, 40, 151-162.

Thamel, P. (2006, November 4). Athletes get new college pitch: Check out our tutoring center. Retrieved from http://www.nytimes.com/2006/11/04/sports/ncaafootball/ 04ncaa.html

Topping, K.J. (1996). The effectiveness of peer tutoring in further and higher education: A typology and review of the literature. Higher Education, 32, 321-345. doi:10.1007/ BF00138870 
Toutkoushian, R.K., \& Smart, J.C. (2001). Do institutional characteristics affect student gains from college? The Review of Higher Education, 25, 39-61. doi:10.1353/rhe. 2001.0017

Wolverton, B. (2008, September 5). Rise in fancy academic centers for athletes raises questions of fairness. The Chronical of Higher Education. Retrieved from http:// chronicle.com/article/Rise-in-Fancy-Academic-Centers/13491/

Yoshida, M., \& James, J.D. (2010). Customer satisfaction with game and service experiences: Antecedents and consequences. Journal of Sport Management, 24, 338-361. doi: $10.1123 / \mathrm{jsm} .24 .3 .338$

Yukhymenko-Lescroart, M.A. (2014). Students and athletes? Development of the academic and athletic identity scale (AAIS). Sport, Exercise, and Performance Psychology, 3, 89-101. doi:10.1037/spy0000009 